\title{
Competitive regionalism in the superior east region
}

\author{
Dan Friyia, Ec.D.
}

This paper studies competitive regionalism, specifically analyzing the arguments made by Linda McCarthy's paper which makes a strong case for regional cooperation for economic development (McCarthy, 2000). In relating to the key points McCarthy discussed, including pooling resources for large infrastructure projects, increasing the region's asset profile, and industrial clusters to create new jobs for the region, the author applies the suggestions in a rural Canadian context in Northern Ontario. By comparing the strategies developed by the Superior East Community Development Corporation (SECDC) board and management to create a better environment for regional initiatives, the author concludes with suggested best practices for regional cooperation in economic development.

Keywords: regionalism, competition, Superior East Community Development Corporation (SECDC), Northern Ontario

\section{Introduction}

This paper was recently inspired by a paper by Linda McCarthy in which she considers a number of issues pertaining to Competitive Regionalism including: arguments supporting greater cooperation, challenges to regional cooperation, some suggested best practices, and a brief evaluation of the concept (McCarthy, 2000). McCarthy's paper is written to address the European and United States context primarily as it pertains to metropolitan and urban areas. I felt that there were applications in this article that could relate to the Superior East Region and other rural areas of Northern Ontario.

McCarthy's article makes a very strong case for communities working together in economic development. The arguments include pooling resources for large infrastructure projects, increasing the region's asset profile, and industrial clusters that can create new jobs for the region. McCarthy only deals with communities competing outside of their region. A major difference in our approach to regional cooperation is that the CDC not only supports cooperation by the region as a whole, but it also respects competition within the region.

This subject matter is interesting for a number of reasons. The Superior East Region is a Community Futures area that provides regional economic development services to the communities of Wawa, Chapleau, Dubreuilville, and White River. There is a history of stormy relationships between our communities that has contributed to an under performance of the Community Futures Program relative to other regions. Upon taking over the full Community 
Futures mandate in 1996, the Superior East Community Development Corporation (CDC) knew it had to build better working relationships with the communities in the region in order to be successful. This project is an opportunity to reflect upon the strategies we have implemented to enhance regional cooperation.

As a foundation for the analysis contained in this paper we will review the key concepts contained in McCarthy's article. In order to set the analysis in a rural Canadian context, we will then provide a profile of the Superior East Region and a brief history into how our communities joined to form our Community Futures area. We will then review the strategies that have been developed by the SECDC Board and Management to create a better environment for regional initiatives.

The paper concludes with suggested best practices for regional cooperation in economic development. Clearly our history, in the context of the McCarthy article, demonstrates that a poor understanding of what impacts regional cooperation can result in years of frustration for all the parties and under performance in terms of the intended mandate.

\section{Competitive regionalism: Beyond individual competition}

The McCarthy article focuses on the benefits of communities cooperating in the area of economic development. The article initially focuses on the wasteful practices of communities competing with each other to attract new business to their area. McCarthy argues that these efforts (costs) can often exceed the benefits associated with attracting new business. The costs are defined as tax incentives and the like while the benefits would include increased employment, income, and an increase to a community's tax revenues.

The article suggests that individual efforts to attract new business can range from being a "zero sum" game, which is only a transfer of a business from one locality to another with no increase in employment to a "negative sum." A negative sum situation occurs when the level of incentive provided by a community exceeds the benefits of attracting the new business. The article also compares business attraction to stimulation of local entrepreneurs. The author suggests that promotion of local entrepreneurs can result in a "positive sum" game where no real costs were expended to create economic development.

McCarthy suggests that the resources previously used in attraction strategies for outside businesses could be better used for other purposes. These resources could be applied to investments that create a better environment for business development or in partnership with other communities on large infrastructure projects that could not be successfully implemented without a pooling of resources. 
The McCarthy article is based on larger regions in the United States and European Union. In these communities governments promote regional cooperation in a number of ways including:

- reducing barriers to cooperation and pooling resources;

- encouraging communities in pooling their resources;

- developing programs that support regional cooperation.

The article notes a growing recognition among communities that greater cooperation is an important way to proceed to ensure economic prosperity. A recent report written by David Douglas and Sandra Chadwick concluded that less than one-third of all rural communities in Ontario have the capacity to undertake local economic development. Main capacity shortfalls identified were in the areas of economic development skills, leadership and financial resources. The recognition of these capacity shortfalls has contributed to the serious consideration of regional models for economic development.

The source of regional cooperation can originate in a "Top Down" fashion where it is dictated by senior levels of government or directed through a grass roots approach, "Bottom Up". Generally, the desire to cooperate is based on some funding issue from the senior levels of government. Later in this document we will demonstrate how federal funding from the Community Futures program was the catalyst for creating the Superior East Regional initiative.

For the purposes of the article, regions are defined both spatially and administratively. Spatial relationships include distance and geography while administrative issues include governance relationships for the delivery of programs such as education, and social and health services. As will be presented later, the Superior East Region is extremely large and has a number of jurisdictional issues ranging from overlapping school and district services boards and other government ministries.

According to McCarthy, the level of participation among the group ranges from large infrastructure projects such as telecommunications, training and education and highways, to "light" efforts such as sharing best practices or regional marketing. The level of participation can also be defined by either a short or longer-term duration of a given project. The level of participation in regional cooperation can also be affected by factors related to distance such as:

- non-contiguous regions;

- lack of awareness;

- institutional frameworks.

These factors suggest that the location of communities in relation to each other and other communities on the outer edges of a region can influence the level of participation on a given 
project as well as the desire to participate. Other interesting issues surrounding the desire of communities to participate in regional economic development include:

- the number of participants in the region;

- the extent of economic disparities between communities;

- ownership (competitive drive) over local economic development;

- central locations (competing communities that act as service points containing superior amenities such as retail, education and health services).

\section{Potential benefits to regional cooperation}

McCarthy points out a number of potential benefits that could accrue to individual communities through participation in regional cooperation. The benefits outlined in the article included pooling of resources for larger projects, improving the "asset profile" to attract outside businesses and the formation of industrial clusters for economic growth.

\section{Pooling of resources}

The undertaking of larger projects such as infrastructure is a very significant benefit resulting from regional cooperation. Smaller communities often lack the capacity to implement large projects due to resource shortages in a number of the areas presented below:

- critical mass as it pertains to population;

- skill shortages;

- financial resources;

- political influence.

This would apply to investment opportunities such as expensive infrastructure projects, the development of a training facility, or as in our case, the establishment of a Community Futures Program.

\section{Asset profile of the region}

No one questions the merits of working with the local entrepreneurs as legitimate means of economic development. It has often been stated that as much as 80 per cent of new jobs in a community are created by local businesses. At the same time no communities are willing to ignore the major impact that a new development can have on the local economy.

The concern here is that many small communities lack the basic asset profile to attract large businesses to their communities. The assets of interest to a large company include: 
- a large skilled labour force;

- transportation infrastructure;

- telecommunications;

- access to raw materials;

- education and health services; and

- amenities relating to quality of life issues.

McCarthy argues that communities within a region can combine their assets to enhance the overall asset profile of a region thereby making the attraction of new industry more likely.

Communities can also contribute to the asset profile of the region by investing in infrastructure projects that are attractive to potential business. This is also true for the development of training initiatives that could result in a more skilled workforce in the region.

A concern that can act as a barrier to regional cooperation is that the benefit of a new industry in one community may hurt the other communities as new jobs may require people to migrate from one community to another to be available for work. The development can actually weaken some of the local economies due to loss of population and total income as people move to where the jobs are.

It is uncertain that the entire community will benefit from the establishment of a new industry in a region. Given the population trends in northern Ontario communities and small business's sensitivity to population levels, regional cooperation could conceivably be difficult to achieve.

\section{Industry clusters}

Industry clusters describe a conglomeration of similar businesses active within a region. These businesses are actively competing and collaborating in horizontal and vertical networks across a region. A good example of industrial clusters is found in the technology-based Silicon Valley in California. For a successful cluster to exist a critical mass consisting of the following assets is required:

- skilled labour;

- infrastructure;

- raw materials;

- associated services.

The creation of industrial clusters allows a region to develop a competitive niche in international markets, transfer knowledge between companies, engage in strategic alliances, enjoy a stable 
workforce and cooperate and benefit from infrastructure investments. Since there is no limitation to the type of industrial cluster that can exist, it can then be assumed that any region is in a position to promote strategic relationships between companies. The largest employer in the Superior East region is the forest industry with six mills operating in the region. Examples of potential partnership opportunities relate to the development of training and education programs and value added wood applications.

\section{Policy concerns}

The concept of regional cooperation presents several benefits to senior levels of government. Certainly it is more cost effective for governments to provide support, financial or otherwise, to regions rather than individual communities. The article presents a good case for regional cooperation. Instead of supporting individual business attraction programs, communities and regions could be better served through direct expenditures in areas such as infrastructure and employee skills or through the imposition of lower taxes.

The potential outcome of cooperative regionalism could be a "positive sum" game that results in communities cooperating to attract economic development rather than competing with each other. McCarthy suggests that regional cooperation is a policy that is transferable from one area to another. However, she does suggest that there is no single model of cooperation that applies to all regions. McCarthy proposes that senior government support for regional cooperation does not mean or result in the central imposition of regions to the specifications of government. The ultimate choice to participate is the responsibility of the local and regional participants in the first instance. Government should guide the process rather than control it.

\section{Best practice in forging competitive regionalism}

The author provided some advice for government and community participants to consider in the creation and nurturing of regional cooperation.

Economic Capacity: successful cooperation rests on high quality workers as well as quality transportation and communication infrastructure. The savings from non-productive competition could be invested in these areas.

Institutional Capacity: successful regional cooperation requires a system of dynamic and representative "collective governance" both formal and informal. This governance runs across levels of government, industry and non-profit organizations.

Self-Identification: collective consciousness is a foundation for replacing individual impulses with collaboration. 
Active Interaction: Social capital involves relationships of trust, political will and commitment on the part of the participants to pull together for successful cooperation. Key issues here are trust and reciprocity. The author terms this concept as "Civic Infrastructure". She states that this factor may be the most important factor affecting successful cooperation in the region.

\section{Background on the creation of the superior east region}

The Superior East Region began the delivery of the Community Futures in 1987 with the creation of a regional committee and the eventual creation of the Superior East Economic Development Corporation (SEED). Community Futures was a federal initiative offered by Canada Employment and Immigration Commission now, Human Resources Development Canada.

The basic activities of the SEED corporation were to oversee the development and implementation of a regional strategic plan in cooperation with area stakeholders and communities. The basic tasks of SEED appear below:

- assess the strengths and weaknesses of the region;

- assess the potential for economic development and diversification;

- identify regional priorities;

- undertake the creation and implementation of action plans;

- create local capacity to manage economic change.

One of the adjustment options available to the region under Community Futures was the creation of a Business Development Corporation (BDC) which was undertaken shortly after the creation of the Community Futures Committee. The BDC provided lending and counselling services to the region's business community. These services were later expanded to include internet access, a resource library, self-employment assistance programs and innovative programs such as the Northern Ventures Initiative (micro-loans and business plan assistance). The BDC is a tool that promotes a "positive sum" situation, as discussed by McCarthy, by promoting the introduction and expansion of local businesses.

The Region is composed of Wawa, Chapleau, Dubreuilville, and White River and is centered in Wawa 130 miles north of Sault Ste. Marie. The region covers some 13,000 square kilometers that are often impassable in the winter months. Travel time across the region from White River to Chapleau is two and a half to three hours depending on weather and road conditions. The economy of the region is heavily reliant on resource extraction in forestry and mining. Tourism is also a major industry in the region. The communities of Wawa and Chapleau (the largest in 
terms of population) serve as regional service centres for retail, education, and medical and government services. These communities are smaller versions of McCarthy's city centres.

The data provided below demonstrates the level of decline in the region over the periods 1989 to 1998. The declining trends presented below have social and economic implications that ultimately impact the overall quality of life in Superior East.

\section{Regional economy measured in total income}

Statistics Canada data for the region reports that total income to individuals increased 20 per cent from $\$ 169$ million in 1989 to $\$ 202.8$ million by 1998 . Our measure of total income includes the combined wages, pensions, investment income and government transfers for each community in our region.

The total income figures for each community in 1998, in millions of dollars, were $\$ 78.8$ for Wawa, \$74.1 for Chapleau, \$23.2, for White River and \$24.7 for Dubreuilville. A major concern that became evident in 1998 was a drop in total income from \$211 million to \$202.8 million or 3.9 per cent.

Figure 1. Superior east region total income to individuals (\$000's)

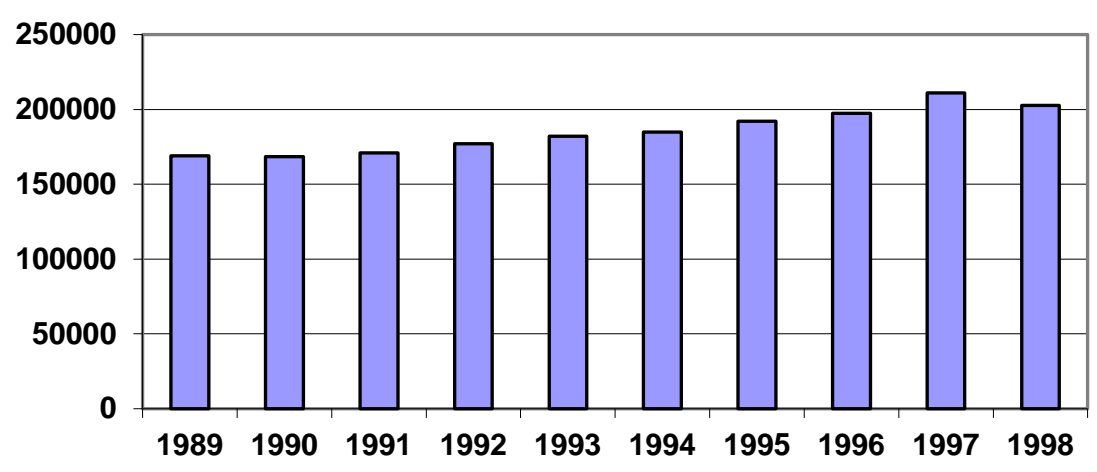

A portion of this drop was anticipated due to the closure of the Algoma Ore Division in Wawa. The closure resulted in a decrease in total income in Wawa from $\$ 83.7$ million to $\$ 78.8$ million. In the same period, Chapleau also saw its total income fall from $\$ 78$ million to $\$ 74$ million, or, five per cent. This drop in total income is of great concern due to the impact on the local businesses, since this sector is extremely sensitive to shifts in the larger economy.

Small businesses are an extremely important component of northern communities. These businesses provide additional sources of income for households and youth and often are the only employment option for some people. A healthy business community also improves the quality of life in a community and its overall attractiveness to new business opportunities. 


\section{Median household income}

The following section on regional demographics will show that the population of the region fell below 10,000 for the first time in ten years. It appears, however, that those who remained in the region had above average family incomes relative to the rest of Canada.

The following outlines the region's performance relative to Canada in terms of median household incomes with families in 1998:

$\begin{array}{ll}\text { Canada } & \$ 57,500 \\ \text { White River } & \$ 71,700 \\ \text { Dubreuilville } & \$ 67,000 \\ \text { Chapleau } & \$ 56,700 \\ \text { Wawa } & \$ 56,800\end{array}$

This income data appears to contradict the claim that the regional economy is weakening. However, while the overall population and labour force has declined, those who remain are government employees whose numbers will eventually decline due to a fall in population or are highly paid resource workers with jobs that are also under pressure. It should be noted that the higher incomes were not enough to prevent regional total income from shrinking.

\section{Regional demographics}

In 1998 the population of the region was 9,600 according to the Tax Filer Survey. There has been a steady decrease in population from 10,425 in 1989 to the most recent level of 9,600. The Algoma Ore Division closure in Wawa was a major factor pushing the level below 10,000. Wawa's population fell between 1997 and 1998 from 4,270 to 4,010 people.

The population of Chapleau also declined between 1997 and 1998 from 3,690 to 3,560 people. The populations of Dubreuilville and White River have remained fairly constant over the period under review.

\section{Regional population trend}

A review of population composition over the ten-year period from 1989 to 1998 shows a trend of an aging population. The only area of significant growth during this period was the over 65 group which increased by 43 per cent. Consistent with out migration trends in Northern Ontario, the group under 29 years declined from 5,440 in 1989 to 4,340 in 1998 or 20 per cent. The drop in children under 15 is even more dramatic at 34 per cent $(3,225$ in 1989 to 2,140 in 1998). 
Figure 2. Superior east labour force trend 1989 - 1998

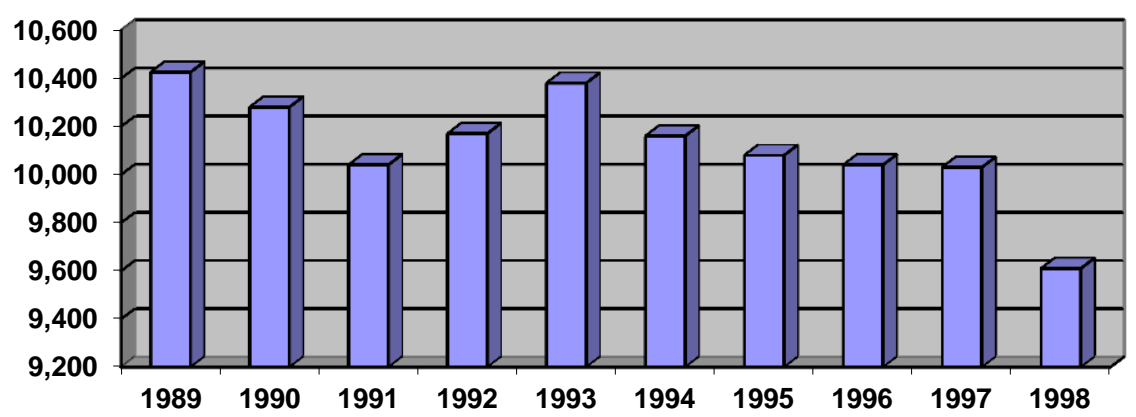

\section{Labour market analysis}

The drop in population is attributed to a declining labour force. The main sources of employment which historically included forestry, mining and more recently government, have been under pressure.

In addition to the decline in population, the Tax Filer Surveys also show a decline in the labour force from 5,850 in 1989 to 5,300 in 1998, a decrease of 9.4 per cent. The recent decline is largely due to the loss of 200 jobs associated with the closure of the Algoma Ore Division in Wawa. A long-term view, however, suggests the decline to be consistent with job losses throughout Northern Ontario in the forest, mining and government service sectors.

The decline in labour force participants represents lost jobs and income that is not replaced. This trend is a concern for the region as it points to an overall weakening of the economy.

The chart below summarizes employment trends for Northwestern Ontario between 1961 to 1996. While some areas experienced employment growth, employment in the mining and forestry sectors, key to northern economies, suffered significant declines. Recently there has also been a decline in the government jobs, which removes a significant buffer that insulated some northern communities from cyclical fluctuations.

Figure 2. Northwestern Ontario Employment Structure

\begin{tabular}{|l|l|l|l|l|l|}
\hline Sector & $\mathbf{1 9 6 1}$ & $\mathbf{1 9 8 1}$ & $\mathbf{1 9 8 6}$ & $\mathbf{1 9 9 1}$ & $\mathbf{1 9 9 6}$ \\
\hline Logging/Forestry & 6,341 & 4,950 & 6,065 & 3,955 & 3,530 \\
\hline Mining & 4,267 & 3,570 & 3,020 & 3,890 & 3,220 \\
\hline Manufacturing & 12,765 & 19,435 & 17,415 & 15,340 & 14,450 \\
\hline Government Services & 3,291 & 9,075 & 10,350 & 14,760 & 9,230 \\
\hline
\end{tabular}




\begin{tabular}{|l|l|l|l|l|l|}
\hline $\begin{array}{l}\text { Other Services } \\
\text { (Including Tourism) }\end{array}$ & 15,789 & 32,555 & 37,295 & 41,630 & 45,795 \\
\hline
\end{tabular}

\section{Economic summary}

The analysis of the region demonstrates a weakening economy highlighted by the following factors:

- declining population;

- declining labour force;

- an early downturn in total income;

- out migration of youth;

- aging population;

- a very cyclical resource based economy.

Each of the noted trends impact the region in a number of policy areas including health, education, economics, the ability to attract new businesses and the overall health of communities. These negative trends can also affect the willingness for Superior East to participate in regional economic development partnerships.

\section{Defining the region}

Five interviews were conducted with members of the original Community Futures Committee and the first General Manager. From all of the discussions held the common recollection of how the four towns of the region were selected for the program included: general location; history of cooperation; and the need for the group to exceed a population threshold of 10,000 people.

In terms of population, the largest communities in the region, which were Chapleau and Wawa had a combined population of 8,325 in 1987. They needed the support of White River and Dubreuilville, each with about 1,000 to achieve the 10,000 threshold.

The communities had previously cooperated in a training exercise called the North Algoma Industrial Training Organization (NAITO). Many of the NAITO members participated in the formation of the first Community Futures committee. At least two members expressed very negative sentiments about the communities working together. Reasons cited for concern about a regional committee were that the communities were very protective of their local economic development initiatives and that the distance between them meant having very little in common.

Local autonomy over economic development is a common sentiment in northern communities that are in a state of decline and perhaps in a battle for survival. Jankowski and Moazzami from 
Lakehead University in their 1996 assessment of Northern Ontario's prospects concluded that the next cyclical downturn in the economy would create pressure unknown in the region's history. Given a comment such as this, it is understandable that individual communities would want to secure any advantage to attract the increasingly smaller number of companies locating in the north.

While individual competition is discouraged by McCarthy, the perceived need to compete by communities in northern Canada should not be underestimated nor should it be trivialized. Manuela Gendron completed a paper in 1998 dealing with the decline of single industry towns. Single industry towns, which are very prominent in rural Canada, were defined as towns where 20-35 per cent of the labour force was employed in a single industry. This is certainly true for White River and Dubreuilville, which are almost exclusively single industry towns with one employer in the forest sector. To a lesser degree Wawa and Chapleau are also single industry towns. For instance, 35 per cent of the workers in Chapleau are in forestry, 22 per cent are in the related transportation sector, 20 per cent work in government services with the other significant sector being retail related jobs. Fifty-seven per cent of the labour force is engaged in forest sector related activities which support most of the retail sector and associated government jobs.

Gendron's paper outlines four main stages of development for single industry towns including construction, recruitment of citizens, transition period, and maturity. The stages describe the evolution of a town that exploits natural resources such as minerals, forestry or fisheries; growing from an industry controlled town to one that is democratic in terms of control.

The maturity phase of a single industry town is characterized by a stable economy, an increase in retirees, a lack of employment mobility among adult workers and an exodus of youth. The Superior East Region analysed from the perspective of population characteristics and income coincides with the maturity phase described by Gendron.

Gendron identifies two additional stages of development for single industry towns that include the winding down phase and ultimate closure of the town. Communities facing the prospect of these phases are likely to demonstrate a strong competitive drive for economic development.

The wind down phase is characterized by capital divestment, the running down of physical assets and a decline in production. The closure phase clearly represents the abandonment of the townsite. The results of a town being in either the maturity or latter abandonment phase are loss of jobs and population, potential social problems, declining property values and lost wealth. No community could be faulted for wanting to avoid this outcome by engaging in competitive local economic development. 
There have been several events in the region over the past few years that raise some concern over the possible movement beyond the maturity phase described in Gendron's paper. These include: the closure of the Algoma Ore Division in Wawa (that resulted in 200 jobs leaving that community); the Lands for Life process that resulted in a reduced access to wood supply which threatened the viability of some mills and in some cases communities; and the current Softwood lumber dispute with the United States.

As the region was being formed, the sentiment of control over local economic development was strongest in the communities of Wawa and Chapleau, which had the largest and most diverse economies. Due to their strategic locations, both communities serve as regional centers for various services for the surrounding communities. In these communities the local business people are the most eager to protect and enrich their investments through economic development.

A study conducted in 1998 by the CDC dealing with shopping patterns in the region illustrated the complex relationship that exists among some of the communities and also demonstrates how local economic strategies undertaken by the communities can complicate regional cooperation. Basic local economic development strategies include:

- attracting new basic employers;

- improve the efficiency of existing firms;

- improve local business ability to capture outside dollars;

- encourage new business formation;

- increase aids/transfers received.

Studies showed that the communities of White River and Dubreuilville had very high levels of out shopping. Between 40 and 50 per cent of total expenditures ( $\$ 5.5$ million conservative estimate) leaked out of these communities. Studies also revealed that the vast majority of these expenditures were supporting Wawa's retail sector. Clearly, the implementation of strategies that reduce leakages in White River and Dubreuilville are detrimental to Wawa's economy.

It has been estimated that one retail job is sustained for every $\$ 100,000$ of sales by a business. As a result, the leakage of $\$ 5.5$ million from White River and Dubreuilville supports approximately 55 jobs in Wawa. These jobs represent an inability to retain wealth, loss of employment opportunities for youth, loss of spousal employment opportunities and generally a lower quality of life in the smaller towns.

Local businesses would also gain significantly from the attraction of a new basic employer to their communities. Given the decline in population and the labour force, a new business would not only be treasured, but provide significant benefits to a local economy. So, it is fairly clear that the tendencies toward individual competition among communities can be attributed to the 
serious economic realities arising from their resource based structure. It is also clear that these tendencies will have to be considered seriously as one tries to implement regional economic development.

\section{Superior east development association (SEDA)}

The life of SEED was never really very settled. The committee lasted only five years when the community of Chapleau pulled its support due to a lack of satisfaction in the services being provided. The communities were then offered another option for regional economic development that included funding from the provincial Municipal Economic Development Assistance (MEDA) program, contributions from townships based on population size and from the federal government's Community Futures Program.

This did not represent a desired option for the communities. In the late eighties and early nineties, the communities of White River and Wawa had received provincial support from the MEDA program to operate local economic development strategies. Chapleau was very close to securing funding for their economic development corporation having completed a significant amount of work to meet the MEDA criteria. Being part of a regional organization was not their first choice.

The new organization called the Superior East Development Association (SEDA) was grudgingly accepted by the communities as it offered a local economic development function in Wawa and Chapleau with Dubreuilville and White River sharing an Economic Development Officer. Negotiations to create the corporation were complicated by this being a forced arrangement that meant sacrificing local autonomy over economic development.

The process of creating SEDA was further complicated by the federal government's decision to amalgamate the Community Futures Committees with the Business Development Corporations. Most BDC's did not want to amalgamate with their Community Futures Committee. This sentiment was also strong in Superior East which greatly complicated the process of getting the regional economic agenda off the ground.

SEDA only lasted from 1994 to 1996 when Chapleau and Wawa removed their support for regional economic development. Prior to the final withdrawal, a weekend planning session was held to try and salvage the project. Representatives from each community attended including local politicians, SEDA, BDC staff and board members, as well as representatives from the provincial and federal governments. The session resulted in a consensus on how the amalgamated corporation would operate. Unfortunately, the proposal was rejected by both the provincial and federal governments which precipitated the withdrawal of Chapleau and Wawa from the project and the ultimate death of SEDA. 


\section{Out of the ashes}

The withdrawal of community support from SEDA left the organization unable to operate at the level intended. The Board of Directors of SEDA was left discouraged, confused and hurt by the actions of all parties concerned. As a result, they decided to dissolve the corporation leaving the Business Development Corporation as the only Community Futures organization left to serve the region.

As the Business Development Corporation (BDC) began to consider the prospects of undertaking the full Community Futures mandate they were left to contemplate several questions.

- Does the Regional approach to economic development make any sense at all?

- Where would we start to pick up the pieces?

- What are some of the lessons learned?

- Who would want to work with us?

- Was the region created properly in the first place or should it be changed?

- Were we being promoted to captain the Titanic?

This was a sensitive yet important time for the Community Futures program in the region. In the history of regional economic development starting with the initial SEED committee to SEDA, little had been achieved other than a tremendous amount of bad blood between the communities and a bad taste for regional cooperation.

These issues were of great concern to the BDC Board, and perhaps of even greater concern was the weak relationships that existed with the federal government following resistance to the amalgamation of the BDC and Community Futures Committee. Not only was the federal connection the major source of funding for the program, it also provided guidance and information for ongoing operations, project development and other key areas.

The first step in the process was to improve relations with the consultant from FedNor. Actually, the opportunity to repair this damage was extended by FedNor through participation in a working group on self-sufficiency of Community Development Corporations.

Another effort to improve the relationship with FedNor was to participate on a steering committee to create what is now called the Northeast Network of CDC's. The network was created to enhance communication and professional development among the members, and most importantly, as a mechanism for dialogue with FedNor management. These projects were good opportunities for the organization to reposition itself within the Community Futures Program. 
A second major step was to contact all client communities to inform them of the new mandate. Input was obtained on several matters such as board membership/representation, advice on past successes and failures, regional relations, realignment of the region and the types of projects that should be pursued. Although difficult, the process resulted in an initial working relationship based on consultation, accountability and reasonable expectations.

The third step taken by the CDC Board was to improve the capacity to perform economic development for the region. In 1996 the General Manager was sent to Year 1 and Year 2 of the Economic Development Program at the University of Waterloo. This professional development was critical to the CDC's success in the long run. It resulted in a strong grasp of the fundamentals of economic development and the opportunity to establish an enormous network of economic development professionals from across Canada.

The topic selected for the manager's Year 1 paper was a strategy to help the Business Development Corporation make the transition to the full economic development mandate. The paper clearly identified the BDC's weakness in the area of economic development and the difficult environment that existed at the time. The paper also identified that the BDC had certain strengths that it could draw on such as a track record in business development and strong board and staff that were respected in the region.

The paper laid out six strategies for the CDC to follow to increase their chances of success at regional economic development.

1. Improve capacity to perform economic development.

2. Provide high quality service to small businesses and community clients.

3. Regional strategies should be created with the input of the communities.

4. Use business success as base to promote credibility.

5. Be accountable to the communities through the sharing of the annual work plan.

6. Continue to work towards self-sufficiency to improve corporate strength.

It was the opinion of the adjudicator of the paper that the road would be difficult for the new CDC. His opinion was that the CDC should take time to build trust and credibility with the regional partners. With this wisdom as our guide, the new CDC set off to perform its new mandate. What is presented below are the specific strategies undertaken by the Board to enhance the chances for success in the region.

\section{Strategies for regional cooperation}

The CDC was given the authority over the regional economic development mandate in 1996. The evolution from a business development corporation to an economic development 
corporation required an update in the CDC's articles of incorporation and a review of Board membership and recruitment strategies. After a discussion with the client communities, it was decided that each community, regardless of size, would be given two board members.

These initial meetings with the communities were important for a couple of reasons. As was stated earlier, they provided a chance to build relationships between the CDC and the client communities. There was a lot of discussion about past mistakes and expectations for the future.

The second reason why the meetings were important was because it provided the opportunity for open discussion related to the continued participation of the communities in regional economic development. At least two communities seriously considered not participating in regional economic development. Very importantly, the discussions revealed that the communities would now be participating on a voluntary basis rather than being forced by senior levels of government.

It is also interesting to note that these meetings were held without the participation of federal government personnel. At this point in the process they stood back and allowed the participants to heal themselves and determine future terms of engagement. Support was provided by the federal consultant where required, but this was in a guiding capacity as suggested in the McCarthy article.

\section{CDC discretionary fund}

In 1996 the CDC found itself with a financial surplus of $\$ 20,000$. The CDC had a number of options as to how to allocate these funds including equipment purchases, wage increases, additional staff members or special projects. After reviewing various options, the Board decided that they would share the surplus equally with client communities.

The Board created the CDC Discretionary Fund where the CDC would contribute to local economic development projects developed in each community. There have been a number of interesting projects that the CDC has contributed to including a local Winnie the Pooh Festival in White River, the development of a tourism strategy for Wawa and most recently a student intern for Wawa to further develop tourism activities.

The creation of the Discretionary Fund was a very strategic decision on the part of the Board of Directors. First of all, each community received an equal $\$ 5,000$ share of the surplus, consistent with the CDC's principles of fairness. Secondly, these financial contributions created real partnerships between the CDC and each community. 
As a final note, the program did not require the communities to tie their projects into a regional strategy thereby respecting the local autonomy and needs of each community. This policy is somewhat contrary to McCarthy's notion of pooling resources, but the Board felt that these contributions were an investment in building trust, partnerships and cooperation which were cornerstones of McCarthy's arguments for regional cooperation.

While the CDC Board deserves a great deal of credit for their decision to share the surplus with client communities, this policy also required the blessings of FedNor. CDC operating contracts are based on cost recovery and as such the surplus should have been returned. FedNor's policy of allowing the CDC's to retain the surplus to be used for local economic development projects allowed the CDC's to become financial partners at the community table. The policy also recognized that the many projects in rural areas are small in nature and often only require small financial assistance to become a reality. FedNor's concession to retain the surplus was a major contribution in establishing credibility and opening municipal doors for the CDC.

\section{Communications strategy}

The CDC undertakes a number of activities to promote itself and the region on an ongoing basis. The normal channels of communication include news releases, promotional strategies, participation in local trade shows, speeches to local groups, advertising and an annual meeting. The CDC is guided by the principle of promoting a regional identity as was suggested by McCarthy, and promoting only those successes that reflect the cooperation of regional partners.

A prime example of the CDC communications strategy is found in the Superior East CDC web site, www.superioreast.on.ca. The site begins with a regional overview including the indicators described below, and then breaks out into specific information on each community. The site is designed to promote a regional identity while also allowing for the promotion of the communities individually.

\section{Regional indicators}

The CDC gathers statistics on the region on an ongoing basis. The primary source of data is the annual Statistics Canada Tax Filer Report. This report provides useful socio-economic information such as demographics and income data. The data is very useful to local entrepreneurs and planners to identify emerging trends in their communities. The CDC provides the data on each individual community as a service free of charge.

The CDC has also undertaken to use this data to produce indicators designed to identify emerging trends for the entire region. Presenting the data in a combined format is another attempt to create a regional identity rather than just a collection of towns in close proximity. 


\section{Project selection strategy}

The CDC has a regional mandate. As a result, an attempt is made to select projects in the annual plan that will provide strategic benefits to the region as a whole. The sample list below illustrates the diverse set of activities and partnerships the CDC has been engaged in since 1996 when it took on the community futures mandate.

$\begin{array}{ll}\text { CDC Discretionary Fund } & \text { Algoma Ore Impact Analysis } \\ \text { Strategic Planning Dubreuilville } & \text { Wawa Adjustment Committee } \\ \text { Regional Web Site } & \text { Regional Tourism Strategy } \\ \text { Community Profiles } & \text { Chapleau Women's Resource Centre } \\ \text { Regional Retail Consumer Studies } & \text { Challenge Kanada Race } \\ \text { Regional Business Studies } & \text { Connect Ontario Telecom Project } \\ \text { Lands for Life Impact Analysis Winter Impact Analysis } \\ \text { Business Resource Centers } & \text { Community Access Projects (4) } \\ \text { Regional Mayors Meetings } & \text { Regional Tourism Strategy } \\ \text { Regional Cellular Phone Studies } & \text { Maintenance of Integration Partnerships } \\ \text { Algoma Trails Committee } & \text { Northern Ventures Initiative }\end{array}$

Recent examples of projects that have been undertaken include: studies for the introduction of cellular phone services in the region; development of a forestry strategy; the creation of a regional tourism commission; and applications for regional snowmobile trail development. Each project extends across the entire region and beyond. They require large resources to implement thus requiring the cooperation from all the towns in the region, as well as from neighboring regions.

The CDC has a strong history of providing loans where traditional lenders have avoided participation. The CDC makes every effort to ensure that these loans are distributed equally in the region. The CDC's loan performance as of December 31, 2000 appears below:

\section{Total Value of Loans Issued}

Total Number of Loans Approved

Average Size of CDC Loans

Full-time and Part-time Jobs

Cost Per Job Created or Maintained

Funds Leveraged
$\$ 6,101,033$

201

$\$ 30,353$

1,063

$\$ 5,739$

$\$ 5,854,069$

The CDC has also implemented projects and services that originated from FedNor. Examples of these projects include Community Access Points (CAP Sites), the Canada Ontario Business 
Services Centres, Northern Ventures and Business Planning Initiatives and the Local Initiatives Fund. These new programs provide innovative and important services to clients, and also enhance the CDC's relevance to clients in the region.

The CDC has implemented a large number of projects with both regional and local focus and has accessed in excess of \$3 million dollars for projects and operations from FedNor since 1996.

The Board's commitment to staff development has given the team the tools they need to perform their duties at a high level. Examples of the professional development supported by the Board include University of Waterloo training in economic development, Small Business Counselling Certificate courses through Confederation College, participation in selected conferences such as the EDCO and the Ontario Association of CDC's annual conferences. In addition, the Board realized that in order to perform at the desired level and to accomplish participation in regional economic development, the people who do the work need to be selected carefully, equipped to perform the work and properly compensated.

\section{Community integration partnerships}

As was described in the McCarthy article, many communities have a strong desire to maintain autonomy over local economic development. The CDC has always recognized this sentiment while trying to balance this with the regional mandate. For the past two years the CDC has maintained community partnerships with each client community to provide local economic development services. With the assistance of FedNor, the CDC contributes fifty per cent of the operating costs associated with these projects with the balance matched by the communities.

Each partnership extends to all of the CDC's services while undertaking local economic development projects. While the projects were initially viewed as a cost effective way to deliver CDC services to a large region, they have also served to increase the social interaction between CDC staff and municipal officials. This interaction has contributed to the creation of "social capital" in the region as referred to by McCarthy. Currently, it is common to be working with local officials on specific projects while assessing their support for certain regional initiatives.

\section{Self-sufficiency of the corporation}

This goal has diminished due to increased funding from FedNor and outside income sources. The CDC, however, has amassed total financial assets in excess of \$3 million through contributions to the Investment Fund from FedNor and through the growth of the fund over time. Once again the CDC has benefited from FedNor's initiative to raise the contribution caps for the Investment Fund from $\$ 1.55$ million to approximately $\$ 3$ million. FedNor has also secured an increase in the CDC's annual operating contributions from $\$ 200,000$ to $\$ 250,000$. 
The increased operating dollars allowed the CDC to hire a Regional Economic Development Officer. This position has greatly increased the CDC's capacity to perform economic development. The CDC's financial position allows for the Board to undertake long term planning and projects that may not come to conclusion for three to five years. This improved financial position also allows longer-term commitments to be made to employees and provides more support for training.

\section{Regional reeves and mayors group}

The Regional Reeves and Mayors Group can be described as an Ad Hoc Working Group that meets monthly to discuss issues of concern. The CDC in conjunction with the local Member of Parliament prompted the initial meeting to discuss the CDC's work plan for the coming year. It was stressed that the best prospect for success would require the cooperation of the entire group.

Since its inception, the group has addressed issues surrounding the downloading of services to municipal taxpayers, District Services Boards, the lack of cellular phone services in the region, the loss of operating grants for local airports and the impact this has on the asset profile of the region. The group has also issued joint statements, such as a united stance on the Lands for Life process that threatened jobs in the region.

The existence of this group is deemed critical to the success of regional cooperation. The McCarthy article refers to this type of relationship as "Civic Infrastructure", or a type of glue that holds together a region. The membership of the group includes the most important "leaders" in the region including the Reeves and Chief Administrative Officers. These people have significant moral and legitimate power to commit their communities to cooperative initiatives in the region. Some initial and positive results include:

- stronger lobbying efforts and common positions;

- sharing of information;

- closer community relations;

- commissioned work to the CDC in the area of cellular phone service.

Interaction with this group has been very instrumental in raising CDC's credibility in the region. The group's combined support for projects has made funding applications more viable at both the federal and provincial levels through their larger voice and the financial contributions they may make to projects. Finally, working closely with these leaders has created additional bonds of friendships, shared experiences, common goals and increased trust that McCarthy describes as a foundation to regional cooperation. 


\section{SECDC opt-out policy}

Up to this point the focus has been on positive strategies to promoting regional cooperation. McCarthy's article does not specifically deal with the subject of ongoing competition within a region. There have been many instances in the region's history when cooperation was not a common approach to economic development.

In the past projects were created requiring the participation of all communities in order to proceed. This situation often resulted in one or more communities using this condition as leverage to try and extract additional benefit from a project, or possibly to sabotage a project entirely.

The CDC Board decided that the best way to approach regional projects was to encourage any community that felt its interests were not being met to opt out of what was presented. This would allow the communities interested in participating the freedom to proceed unimpeded while allowing those not interested the ability to pursue their own priorities.

This approach respects individual autonomy over local economic development activities even to the point of being in competition with the other communities for new business opportunities. It also respects the rights of the remaining communities to work in cooperation on the proposed project. This strategy appears to have had the effect of communities acting in a more responsible manner, as no community has opted out of any project nor attempted to use their non participation as leverage.

\section{Conclusion}

The CDC has been very successful since taking on the full Community Futures mandate. This fact is supported not only by the projects that have been implemented and the dollars accessed for the region, but strong relationships the organization has formed within the region. The Board of Directors deserve a great deal of credit for the vision and leadership that they demonstrated from the difficult early stages to the current situation.

In giving credit where credit is due, the CDC also acknowledges the strategic assistance that FedNor has provided in terms of the innovative programs that have facilitated the CDC's pursuit of its mandate. FedNor has also secured increases to operating and investment activities allowing CDC's to expand their capacity, and has been very flexible in its approach to issues such as operating surpluses. This assistance has been very instrumental in providing the CDC with the strategic tools needed to build credibility in the region and provide excellent service to clients. 
After a review of the facts, CDC certainly supports competitive regionalism in a manner described by the McCarthy article with the exception of respecting competition that legitimately occurs in the region. Creating a successful regional economic development program is a tall order for any group mandated the task. Based on the experience of the CDC, it is recommended that the following considerations be incorporated early in the planning phase to enhance the chances for success.

\section{Embrace the regional model}

There are many good reasons to embrace the regional model for local economic development including:

- the opportunity to eliminate zero sum games;

- the potential to improve the asset profile of a region to attract new business;

- the critical mass and large financial resources that are often beyond the capacity of any one community;

- to meet senior government program funding criteria;

- to secure the resources required to conduct a professional economic development program which generally exceeds the capacity of smaller communities.

\section{Consider the dynamics and relationships of the partners}

When governments are in the process of creating a region it is important to review some of the factors presented below. Many problems and years of frustration can be avoided with a greater understanding of the following:

- history of relations between communities;

- the geographical relationships of the targeted communities to each other and neighboring communities;

- McCarthy's definition of "City States" and how this affects participation in regional projects.

Participation should be voluntary where ever possible. Past experience demonstrated that when the communities were forced into participation there was no long term buy in to the project. Under the current working environment, the towns' basis for participation is completely voluntary. The SECDC respects their right to autonomy for local economic development with its "Opt out policy" which allows a given community to withdraw from a given project without impeding the wishes of the entire group. 


\section{Regional leadership}

Not enough can be said about leadership. Considerable discussion on this subject is found throughout the literature on community economic development. Leaders have power that is attributed to their positions, arises from specialized knowledge, or is the outcome of respect for past work. People follow leaders and the literature continually reinforces the fact that leaders are needed to champion successful projects.

The Regional Reeve group is critical to regional cooperation. They are a collection of elected leaders with a tremendous amount of influence in their communities. Having these people work together on regional issues is a large step towards regional cooperation and increased credibility for the CDC.

\section{Ongoing vigilance towards relationships}

The relationships between the towns will change. Elections will bring new Reeves and Councilors, new municipal CAO's and EDO's will be hired, government programs will come and go and economies will change.

- learn the players in the game;

- learn the rules in particular as it pertains to EDO's non-participation in politics;

- be patient, political decisions take time;

- be flexible and allow for input from the partners to increase ownership and participation.

\section{Credibility is earned through performance}

In the end the organization has to perform and be relevant to the community it serves. The worst thing an organization can do once it gets support from a region is to disappoint the group. Some suggestions for building credibility involve:

- developing a track record;

- being accountable to the communities with a regular communications strategy;

- building and honoring personal relationships and commitments;

- acknowledging the contributions of the partners.

The CDC Board has presented a number of strategies for regional cooperation. So far there has been a greater acceptance of regional economic development. All parties would have gained from the benefit of McCarthy's research if it had been available back in 1987. 


\section{Author's biography}

Dan Friyia has served as General Manager for the Superior East Community Development Corporation for ten years, located in Wawa. He is on the Advisory Board of Algoma University Community Economic and Social Development Program. Dan holds a B.A., H.B.Comm. and M.B.A. He has a Certificate in Economic Development from the University of Waterloo and the Economic Developers Association of Canada, and has received Professional Accreditation in Economic Development from the Economic Developers Association of Canada. He has a number of special interests including music, golf, reading and spending time with his family. Dan and his wife, JoAnna, are the proud parents of Daniel, who is nine years old, and Samantha, who is six years old.

\section{Bibliography}

Douglas, David and Sandra Chadwich, Toward More Effective Rural Economic Development in Ontario, School of Rural Planning and Development, University of Guelph, Technical Report \#2 (Edition 1), 2001.

Friyia, Dan and Tina Tarini, Regional Retail Studies for Superior East, A Publication of the Superior East Community Development Corporation, Wawa, Ontario, 1997.

Gendron, Manuela. “Sept-lles: A Town's Struggle for Survival”, Papers in Canadian Economic Development, Economic Development Program University of Waterloo, Vol 2. pp. 57 - 78, 1988

Jankowski, W.B., and B. Moazzam, Northern Ontario at the Cross Roads, Strategic Publications Press, Thunder Bay, Canada, 1996.

Jeffery, Bob, "The Regional Solution, Economic Development in Rural Canada", The Economic and Technological Development Journal of Canada, pp. 86-88, 1999.

Luther, Vicki and Milan Wall, The Entrepreneurial Community: A Strategic Leaderships Approach to Community Survival, A Publication of the Heartland Center for Leadership Development, Lincoln, Nebraska 68508, 1989.

McCarthy, Linda, Competitive Regionalism: Beyond Individual Competition, Reviews in Economic Development Literature and Practice: No 2, US Economic Development Association, October 2000.

Shaffer, Ron, Community Economics - Economic Structure and Change in Smaller Communities, Iowa State University Press. Ames, Iowa 50010, 1989. 
Shaffer, Ron, Glen Pulver and Ronald Hustedde, Community Economic Analysis: A How to Manual, North Central Regional Centre for Rural Development. Iowa State University, Ames, Iowa IA 50011-1070, Third Printing - April 1996.

Smith, Anne and Flo Frank, The Community Development Handbook: A Tool to Build Community Capacity, Ministry of Public Works and Government Services Canada 1999.

Tax Filer Community Profiles, Statistics Canada - 1989-1998. 